\title{
Benefits of Participation in Sport to the Youth
}

\author{
Olanipekun Johnson Adetunji, Ph.D ${ }^{1}$, Akindutire, Isaac Olusola, Ph.D ${ }^{2}$ \\ ${ }^{1,2}$ Department of Human Kinetics and Health Education, Faculty of Education, Ekiti State University, Ado-Ekiti, \\ Nigeria.
}

\begin{abstract}
Boosting participation in sport can generate variety of profound and positive impact on socioeconomic and health benefits on individual, community and wider society. Regardless of age groups, being physically active can help individuals enjoy physical fitness towards wellness and live healthier lives. This paper therefore, highlighted the concept of sport, characteristics and its types. It focused on the forms of sport programmes and the benefits of sport participation among youth. Issues related to the threats against active sport participation among youth and strategies for advancing the level of sport technology development in African continent were discussed. Towards the benefits of effective participation in sports among the youth, it was therefore, recommended that sport personnel including physical education teachers must be qualified, competent, and seasoned as prerequisites for a successful sport programme. The various post-primary schools and tertiary institutions should survey and explore other feasible sources of raising funds from sport ministries, philanthropists, voluntary agencies, and multinational companies to supplement the students' sports fees; and adequate good quality sport facility, durable equipment and supplies should be provided with incentives to motivate athletes.
\end{abstract}

Keyword: sport, strategies, youth, sport programmes, benefits, threats.

\section{Introduction}

It is a difficult task to identify the real concept of sport because of the diverse meaning it portray to peoples at different levels and different occasion Sports, all over the world has become an established entity that exert great influence on social, political and even the economic environments of any nation and that of individuals. The Oxford Dictionary (1990) defined sports as an activity engaged in especially outdoor for amusement and exercise, while Mbaye (1999) defined sports to be a group of physical exercises that may be organized into individual or team games with one specific rule. Sport is a general name that is used when one is referring to activities requiring competition between two or more people (Ajisafe, 2009; Mangan, 2011). It is one of the major components of Human Kinetics (Physical Education) with athletics, gymnastics, dance, swimming, wrestling, cycling and games. Sport are stabilizing factor that keeps participants against dangers of modern civilization which are now prevalent in different societies. Experience has shown that sport can achieve what it takes peace talk, diplomatic treaties and conferences a longer period to achieve. For instance, it is only sports that could, in a short time bring warring nations together e.g. the Jews and the Arabs, England and Argentina, Ghana and Togo to list a few.

Considering the Olympic standard, sports is best described as a game of occurrence, an institutionalized game, as a social institution and as a social system (Coakley, 1982). This portrays sport as an activity that is competitive in nature, having both intrinsic and extrinsic motivations, while any activities that do not fall within the domain of the definition could be termed as recreation or play. It is a stabilizing factor that keeps the participants against dangers of modern civilization which are now prevalent in different societies. It serves as safety valve for both participants for both participants and spectators dissipating excess energy, tension and hostile feelings in socially acceptable way. Sport is organized or unorganized recreation. Today, sport is by nature, is competitive, following the rules and regulations and beneficial to both who are physically able and disabled. It is selective for the disabled and for this reason, majority of students are excluded from participation in the schools. Less able students tend to become the passive participants who just stand to hail the good performances of their mates. Sport is used as a leisure activity in hunting or fishing wildlife for entertainment rather than for subsistence or for the market.

\section{Characteristics Of Sport}

Sport has so many features that make it what it is today. For any activity to qualify or be regarded as sport, it must be competitive in nature because people struggle to win, using their knowledge, skills and techniques required for performing them. It is educative because it involves teaching/coaching and learning. It has specific rules and regulations guiding them. It is recreational in nature because it enables people to take part when they like and for entertainment for both the participants and spectators watching such performance; and it is performed as an individual activity, dual and team activity (Loy, 1968; Payne, 1990). 


\section{Types Of Sport}

There are various types of sport that are called sport. The major types of sport are outdoor sport, indoor sport, physical development sport and mental development sport (Ojeme and Uti, 1996). These sports may include any of the following:

1. Aquatic sport that take place in water such as swimming, diving, water polo, synchronize, swimming, rowing canoeing etc.

2. Combating sport that requires the use of force on one's opponents such as boxing, wrestling, judo, karate, and taekwondo.

3. Athletics sport that consist of all tracks and field like short and fast distance races, middle distance races, long distance races, hurdles, the throws, the jumps and the vaults.

4. Games as organized competitive activities involving movement skills and played according to the rules and regulations e.g. All African games, Nigerian University Games (NUGA), Nigerian Colleges of Education Games (NICEGA), Nigerian Polytechnics Games (NIPOGA) Games Olympic Games and West African University Games (WAUG). All major games may include the ball games, racket/striking games while the minor games are table soccer, billiards darting and fencing etc.

5. Gymnastics as a sport involving performance of exercises requiring physical strength, flexibility, agility, coordination, balance and grace (Babalola, 2010). The various forms of gymnastics include artistic gymnastics, (balancing on the beam), vaults, parallel bars, floor exercises, use of rings, trampoline and tumbling, aerobic and aerobatic gymnastics, team gymnastics and rope climbing.

6. Recreational sport are movements activities performed during free or leisure hours or time such as horse racing, game shooting, polo game, table tennis, kite flying, ball games running jogging, Ayo game and other traditional or local games and sports. Traditional sports are sporting activities of different cultures of any country involving traditional wrestling, Ayo game/Aarin (pebble).

\section{Forms Of Sport Programmes}

Sport programmes may be in form of intramural sports (intramurals) and extramural sports programmes. Intramurals Intramural sports are recreational sports organized within a particular institution, usually an educational institution or a set of geographical area (Ladani, 2007). This is used to indicate sport matches and contests that take place among teams from within the walls of an ancient city (as opposes to varsity team which competed with the team from other cities or towns. As extension of regular class periods of physical education, intramural sports are those activities that are conducted within the four walls of an educational institution or establishment. Only bonafide students of that institution can take part in the activities).

The purpose of intramural sport include the provision of fun, enjoyment and followership for the students through mass participation in sports; for serving as an extension of the regular physical education period for the participants; for improving the physical fitness status and health of the participants; for encouraging mass participation of all participants regardless of age, sex, races, religion and cultural backgrounds; for common interest of the participants; for practicing good citizenship to make better citizens in the society; for developing fuller cooperation between the home and the school; for developing the good spirit of sportsmanship and provide a basis for more effective counseling and promote better emotional climate (Benman, 2014).Considering these numerous benefits, the organization of sport programmes must be the sole responsibility of the sport educators and assisted by other members of health personnel (Reichert, 2010). The participants should share the responsibility in the planning, development and management of the programme. They should also participate actively in establishing policies, rules and regulations, procedures by serving in various subcommittees. At the University level, it is the responsibility of the University Sports Council in conjunction with the Students' Representative Council and the Students' Director of Sports, to organize and conduct Inter-Departmental, Inter-Hall sports and individual sports tournaments. Good schedule of sports programme, adequate sports facilities and equipment, proper management of fund made available, motivation (reward), school health services and other significant are essential ingredients for effective intramural sports programme (Holley, 1980).

\section{Extramural sport programme}

All sporting competitions done outside the school establishment are referred to as extramural sport programme (Morakinyo, 2003). Extramural sport competitions may be organized on inter-school, intercollegiate and tertiary sports programmes outside the institution e.g. NUGA, Ekiti State Higher Institution Games (ESHIGA) in Ekiti State tertiary institutions and WAUG. Participants in extramural sports are highly skillful and well trained in their various sport and games. They serve as image makers well disciplined and play according to the rules of the game. They always enjoy university recognition and other external rewards based on their performances. The authority concern should ensure that participants are not found wanting in their 
academic pursuit. Participation in extramural sports programmes is a pathway to unity among youths and source of talents hunting for national and international sport team.

Participating in extramural help the participants to improve their skills further and help those who have excelled during the intramural sports programme to improve on their skills. It fosters cordial relationship between the schools that participate in the programme as well as the individual participants. It also helps to evaluate the progress made by the participants of each school human kinetics programme. It enhances physical fitness level of the participants, make more friends with students of other schools and expose participants to higher level of competition in that particular sport. It is a medium of preparing athletes for interschool competitions (Dauer, 2012).

\section{Benefits of Sport Participation Among Youth}

Sport and games are an integral parts of a student life. A student should study hard to be successful in competitive examinations but he should enjoy the benefit of sport participation. Along with academic activities, a student should spend time on games and sport. There are many people who give importance only to classroom learning without provision for extramural experience through recreational activity (J'Heureux, 1964, Ajisafe, 2009). In the western countries, education of the youths is no longer confined to the lecture theatres alone. Monotony of lectures has been very much minimized by outdoor and participation in sports and various athletes feat which generate healthy competitive spirit and interest in life among youths. The issue of inactivity has become an epidemic in Nigeria society, because of the sedentary lifestyle of a large proportion of Nigerian citizens regardless of their disciplines. Inactivity of individual increases the causes of mortality, doubles the risk of cardiovascular diseases, diabetes and obesity and increases cancer, high blood pressure, anxiety and depression (Ojeme and Uti, 1996). The combination of inactivity and overweight is responsible for a great number of sudden deaths in Nigeria in recent times. Thus, there is need for regular participation in physical activities for the purpose of attaining total wellness. However, the benefits of participating in sport according to Opatola (1999); Ajisafe (2009), Ikulayo (1997), Akindutire, Adegboyega, Ajayi-Vincent and Olanipekun (2013) are not far-fetched which include the following:

Sport develops individual physical fitness and health/ organic wellbeing, aid mental growth, facilitates internal unity and boosts external prestige. It also develops qualities of good sportsmanship, winning and losing gracefully, cooperative attitudes, traits of good citizenship and spirit of patriotism, leadership and acceptance of leadership roles. Participation in physical exercises through sport include enjoyment, psychological wellbeing to be effective and reduce depression, anxiety, release of tension and for relaxation; for facing the challenges of life and developing a sense of personal accomplishment (Ajisafe, 2009). It helps youth to learn how to handle adult roles in general and competitive relationship in particular. Sport is a socializing agent that cuts across religious boundary, tribal affiliation and social class. Participants in sport establish permanent friendship and engage in healthy competitions. Sport develops better self-discipline and promotes self-esteem and selfactualization, which is the highest level of human development (Akindutire et. al, 2005).

Through active participation in sporting activities, some degenerative circulatory disorder can be alleviated or postponed. Ajisafe (2009) indicated that many people who suffer from degenerative circulatory disorders tend to be overweight, have high fat and cholesterol diets, live under emotional stress and fail to participate in regular exercises. Playing sport helps the participants stay in shape, improve endurance, boost selfesteem, provide guidance and aid weight control, organize their time, boost friendships, teamwork and build relationships with their peers and adults (Babalola, 2010). Sport brings teenagers together from different schools, background and communities and give parents time to appreciate one another. Providing wisdom and encouragement, coaches can be very good role models and the relationship developed with the coach is very important to the success of the team and push them academically and physically.

Participating in sport improves health and gears the body to achieve peak performance levels and have a positive impact on school (Bucher and Thaxton, 1981). Sport forces the participants to organize their time so that they can both go to practice and finish home work. The key to friendship is to balance succeed in both; build leadership skill through captainship with opportunity to surround the participants with competitive people and role models.Physical exercise is good for mind, body and spirit (Adedeji (1985; Ajisafe, 2009). Thus, team sport is good for learning accountability, dedication and leadership among many other traits. Many athletes do better academically. Sports require memorization, repetition, and learning of skills that are directly relevant to class work. Sport teaches teamwork and helps achieve goal towards victory when encountering problems at work, home or in any areas. Sport offers healthy decisions such as avoiding smoking or drinking and offer hidden health benefits such as lower chance of getting osteoporosis or breast cancer later in life (Payne, 1990). Thus, allowing youth to participate in sports is a fantastic way to explore and develop lifelong skills. It is well known that youth who participate in sports are less likely to drop out of school, and become involved in drugs and alcohol activity, while they are also excel in academic performance aid sociability (Buneman, 2014). Boosting participation in sport can generate a variety of socio-economic benefits. Sport can make a profound 
and positive impact on individual community and wider society. Empowerment through sport connotes that individual in the very active age bracket (male and female) are energized through motivation to be able to assert himself or herself in sport competition and leadership roles (Akindutire, 2005). In USA and England, all local authorities can demonstrate how sport benefits their economy in form of business output and job plus wider benefits like health and physical fitness. For instance, the contribution to employment in even greater sports and sport related activity is estimated to support over 400,000 full-time equipment job, $2.3 \%$ of all job in England (Ladani, 2007). This may reduce youth at risk of criminal behaviours and enhance self-esteem. Playing sport help youth to stay in shape, teaches to organize time, boosts friendships and build relationship with peers and adults.

\section{Threats To Participation In Sport Among Youth}

It is necessary to elucidate certain trends and developments in sport on the outline of its major problems (Ajisafe, 2009 Ojeme, 1989; Shehu, 1993). The contemporary issues and problems faced by the organization and administration of sport programmes in Nigeria in particular and African region in general are legion but briefly include utilization of instructional materials; inadequate resource allocation; escalating students population; coaching time versus teaching time; Lag between discoveries by sp scientists and professional acceptance and usage of knowledge; shortage specialists/manpower; poor curriculum designs and implementation; personality clashes among physical education and sport leaders; cultural and social pressure against majority of women in sport (Adedeji,1985; Akindutire, 2005; Ladani, 2007; Ajisafe,2009). Other significant factors are superstition and misconceptions about human body and health; low turnout of research and professional literature; harmful substance abuse among students and athletes, ethical problems in competitions and relative immaturity and weakness of the profession as a legitimate pressure group.

\section{Strategies for Advancing the level of Sport Technology}

The acquisition of sport technology can be approached in the following ways:

- It is necessary to identify African technological needs in sport. There is the need for African continental survey to establish the actual status of sport technology development.

- Through bilateral agreement with the advanced technological nations, technical personnel could be brought to the various countries in Africa, to impart the technological knowledge and train the athletes in African continent to enhance their sport performances.

- Another significant variable in the whole process is for African government to ensure the prevalence of an enabling environment at home in terms of provision of work and motivation (incentives). Technically trained hands need to be highly motivated in terms of incentives and resources.

- One strategy for advancing the level of sport technology is that it should become the object of curriculum innovation. Therefore, sport technology should be introduced to all tertiary institutions of learning in African countries.

- Industries in African nations must be encouraged to produce sport goods and materials and heavy instrument in the areas of manufacturing and mass production of sports equipment for motivation in the area of participation and performance.

- Technological skills and knowledge must be continuously renewed through continuing education programme.

\section{Conclusion}

It is clear that human kinetics and sport are interdisciplinary issues with long history and scientific tradition. The discipline and the profession have developed through great devotion of sensitive, dedication and intelligent men and women scattered all over the world. Human kinetics and sports have advanced today because of the contributions of many athletes, scholars' administrators, coaches, governments, politicians, military men, teachers, researchers, industrialists. It is noted that the importance of sport organization and administration need to be emphasized to reflect the benefits derived from sports participation among youth. Sports function in several ways especially in character building, discipline curbing crime rate, developing economy, ideology, patriotism, education, mental, social, emotional and physical fitness and health. Thus, there is the need to stress women participation in sports like their male counterparts and examine the problems militating against women participation and involvement in sports.

\section{Recommendations}

Towards the benefits of effective participation of sports among the youth, the following recommendations were made:

1. Sport personnel including physical education teachers must be qualified, competent, and seasoned as prerequisite for a successful sport programme. 
2. The various post-primary schools and tertiary institutions should survey and exploit other feasible sources of raising funds from sport ministries, philanthropists, voluntary agencies, and multinational companies to supplement the students' sports fees.

3. Adequate facilities and equipment should be provided considering the programme needs of each schools; good quality and durable equipment and supplies should be purchased.

4. Curriculum for human kinetics and sport programmes should be well developed and must be progressive in nature from year to year and season to season, providing the best opportunity for students as often as possible.

5. An institute of sport technology and human kinetics studies should be established in each University to produce technical competent individual in different areas of specialization.

\section{References}

[1]. Adedeji, J. A. (1985). The teaching of physical and health education. Ibadan: West Book Publishers Limited

[2]. Ajisafe, M. O. (2009). The role of sport in a developing country. Benin-City: Headmark Publishers.

[3]. Akindutire, I. O., Adegboyega J. A., Ajayi-Vincent O. B. \& Olanipekun J. A.

[4]. (2013). Physical fitness programme. Ekiti State University, Ado Ekiti.

[5]. Babalola, J. F. (2010).Handbook of practical physical education. Ibadan: O.B. F. International Press

[6]. Bucher, C. A. \&Thaxton, N. A. (1981). Physical Education and sport change and challenges. St. Loius: The C. V. Mosby Company.

[7]. Buneman, F. H. (2014). Intramural sports: A test and study guide. Wm. C. brown Company.Coakley, J. J. (1982).Sport and society: Issues and controversies. St Louis: The Mosby Company.

[8]. Holley, B. (1980). Computer coordination of campus intra intramural. JOPER, 51 (4), 50.

[9]. Mangan, J. A. (2011). Definition of Sports in Latin American: Past and present. Journal of American Society. 93.

[10]. Mbaye, K. (1999). Sports and human rights. Olympic review XXVI (24). Loy, J. W. (1968). The nature of sport: A definitional effort. Quest Monograph, 10, 1-15.

[11]. Ojeme, E. O. \& Uti, J. O. (1996). Comprehensive Physical Education and sport. Cameroon: African-FEP Publishers Limited.

[12]. Opatola, G. O. (1999). Sport coaching and competition. In O. A. Moronkola: Essentials of Human Kinetics and Health Education. Ibadan: Codat Publications. Payne, S. D. W. (1990). Medicine, sport and the law. Oxford: Blackwell Publishers. 309.

[13]. Reinchert, D. W. (2010). Guidelines for Intramural and extramural sports programmes. The Pennsylvnia State University, Pennsylvnia.

[14]. J'Heureux, W. J. (1964). Sport in modern culture. Journal of Health, Physical Education and Recreation. 2 (3), 23 -32. 